\title{
Rekreasyon Terapisi Kamplarının Sosyal Etkilerinin Değerlendirilmesi
}

\author{
İpek AYDIN, Özkan TÜTÜNCÜ \\ Dokuz Eylül Üniversitesi \\ Spor Bilimleri ve Teknolojisi Yüksekokulu
}

\section{GiRiş}

Sosyal yönden bireyin kendisini yeterli hissetmesi ile sağlık çıktıları arasında pozitif ilişki birçok çalışmadan elde edilen bulgularla desteklenmiştir (Horn vd. 1998; Orbell vd. 2001). Bunun yanında sosyal özyeterliliğin yaşam tatmini artırdiğına yönelik bulgular mevcuttur (Hampton 2000). Gençler üzerinde gerçekleştirilen çalışmalarda, sosyal özyeterliliğin, psikolojik, sosyal ve davranışsal durumda olumlu etkisinin olduğu tespit edilmiştir (Passmore 2004; Kumar ve Lal 2006). Düşük sosyal özyeterliliğge sahip olan bireylerde depresyonun daha fazla görüldüğü ve yaşam tatmininin düştüğü ve hayata karşı daha olumsuz oldukları belirlenmiştir (Caprara vd. 2006). Özellikle kronik rahatsızlığa sahip olan bireylerde kendi bakımlarını da yerine getirerek hayata aktif katılımlarını sağlamada sosyal motivasyonla ilişkili olarak özyeterliliğin önemi vurgulanmaktadır (Williams ve Bond 2002). Sosyal özyeterlilik bireyin yaşam kalitesi ile ilişkili olduğundan, özellikle hastalık, engel ve bağımlı grupların, sağlık problemleri nedeniyle yaşadıkları sosyalleşme sıkıntılarının da yaşam kalitesi üzerinde etkisi olduğundan hareketle rekreasyon terapisi kamplarında edindikleri deneyimin onların sosyal sağlıkları üzerinde de etkili olabileceği düşünülmektedir. Bu kapsamda, rekreasyon terapisi kamplarının sosyal özyeterliliği geliştirerek, sosyal hayata olumlu etkisi olduğu varsayılmaktadır.

Rekreatif faaliyete katılmak ile bir rekreasyon terapisi kamp programina katılmak arasında belirli farklılıklar vardır. Bunlardan ilki birey kendi yaş grubu, hastalık veya engel grubunda yer alan bireylerle bir araya gelmektedir. İkinci ola- rak, bireyler ikame ettikleri yerlerin (kendi evlerinin) dışında başka bir ortamda belirli bir süre için rekreasyon terapisi kamplarına dahil olmaktadır. Üçüncü olarak katılımcılar daha önce tanışmadıkları bireylerle bir araya gelmektedirler. Son olarak, kendi hastalık, engel veya bağımlılık gruplarına ilişkin deneyimlerini ve yenilikleri paylaşma imkânı bulmaktadırlar. Bu nedenlerden dolayı rekreatif faaliyetlere katılım ile rekreasyon kamplarına katılım arasında fark bulunmaktadır. Gerçekleştirilen kamp programlarının fiziksel ve psikolojik sağlığa olumlu katkılarının yanında sosyal sağlığa etkisinin değerlendirilmesi çalışmanın amacını oluşturmaktadır. Genellikle ülkemizde gerçekleştirilen çalışmalar rekreatif etkinliklerin bireylerin üzerindeki fiziksel, sosyal ve psikolojik etkileri üzerinde durmaktadır. Bu çalışmada belirli bir yaş grubuna, hastalık, engel ya da bağımlılık grubuna yönelik oluşturulmuş kamp programlarının çıktılarının geliştirilmesine yönelik bazı öneriler getirilmektedir.

\section{KURAMSAL ÇERÇEVE}

\section{Rekreasyon Terapisi}

Rekreasyon bireyin yaşam kalitesini artırmak için serbest ve/veya boş zamanlarında, doğaya zarar vermeden gönüllü olarak yapılan faaliyetler şeklinde tanımlanabilir. En genel tanımıyla, rekreasyon terapisi, tedavi sürecinde yapılan rehabilitasyon faaliyetleridir (Tütüncü 2012). Daha detaylı bir şekilde tanımlanacak olursa, rekreasyon terapisi belirli bir hastalık veya sakatlığın olması durumunda, hastalıklarının ilerlemesini yavaşlatmak veya durdurmak, tedavi sürecini destekleyici katkılar sağlamak, hastalık süresince yaşam kalitesini artırmak amacıyla gerçekleştirilen 
rekreatif faaliyetlerdir (Tütüncü ve Aydın 2016). Amerikan Terapötik Rekreasyon Birliği rekreasyon terapisini, travma ya da hastalık sonucu engellilerin bağımsız fiziksel, bilişsel, duygusal ve sosyal işlevlerini yerine getirebilmelerini sağlamak, günlük hayattaki becerilerini geliştirmek ve toplumsal hayata ayak uydurmayı kolaylaştırmak için çeşitli rekreatif faaliyetlerden yararlanılarak oluşturulan terapi şekli olarak tanımlamıştır (Shank ve Coyle 2002).

Rekreasyon terapisi kapsamında yalnızca hastalık ve sakatlık durumunun olması şart değildir, bireyin sosyal ve psikolojik yönden rahatsızlık hissetmesi rekreasyon terapisinin kapsamina girmektedir. Kişinin iyileşmek için motive olması, kişinin sağllı̆̆ ile ilişkili bir durumdur (Williams vd. 2002). İyileşmek için motive olan bir kişi, psikolojik olumlu etkilerle daha hızlı bir sürede daha iyi bir duruma gelebilir. Rekreasyon terapisi ile bireyleri sağlıklarının daha da iyiye gideceği yönünde motive edilmekte ve sosyal, fiziksel ve psikolojik açıdan onların sağlıklarının gelişmesine katıda bulunulmak amaçlanmaktadır.

Rekreasyon terapisi, dünyada genellikle gruplara özgü oluşturulan kamp programları ile gerçekleştirilebilmektedir. Bu kamplara rekreasyon terapisi kampları denilmektedir. Bu kamplar dahilinde hedef yaş, hastalık, engel veya bağımlılık gruplarına yönelik kamp programları oluşturulmakta ve onların hem tedavilerini destekleyecek hem de yaşam kalitelerini artıracak rekreatif etkinlikler gerçekleştirilmektedir. Özellikle kronik rahatsızlığı çocuklarda ve gençlerde, rekreasyon terapisi kampları, bu grupların sorunlarının ele alınmasında önemli bir rol oynamıştır (Winfree vd. 2002). Rekreasyon terapisi kamplarında, grup olarak gerçekleştirilen rekreatif faaliyetler, bireylerin sosyal ilişkiler kurmasında ve geliştirmesinde büyük rol oynamaktadır. Bu kamplarda, yeni arkadaşlıkların oluşması, grup içinde yer edinme ve diğer grup üyelerini tanıyabilme gibi çabalar, kişinin sosyal yaşantısını etkileyerek olgunlaşmasını ve toplum hayatına alışmasını sağlamaktadır (Karaküçük 1997).

Bireylerin sağlıklarını iyileştirmek ve geliştirmeye yönelik gerçekleştirilen bu kamp programları, fiziksel, sosyal ve ruhsal yönde sağlık üzerinde etkili olabilir (Bekesi vd. 2011). Rekreasyon terapisi kamplarının hedef aldığı yaş veya grubun çok iyi tanımlanması, tıbbi konularda destek alınması ve bu doğrultuda planlamanın gerçekleştirilmesi gerekmektedir. Gerçekleştirilen birçok çalışmada farklı gruplara farklı kamp programlarının, olumlu çıtılarının olduğu tespit edilmiştir (Punnett ve Thurber 1993; Briery ve Rabian 1999). Doğru planlanan rekreasyon terapisi kamplarında kronik rahatsızlığı olan çocuklar ve gençler de farklı yararlar sağlamaktadırlar (Walker ve Pearman 2009). Özellikle kronik rahatsızlığa sahip olan çocukların psikolojik yönden de desteklenmesi gerekmektedir (Kiernan vd. 2004) ve bu kamplar, çocukların farklı rekreatif etkinliklere katılarak hem eğlenceli zaman geçirmelerine hem de fizyoloji, psikolojik ve sosyal yönden sağlıklarının iyileşmesi ve gelişmesine olanak sağlamaktadır.

Kamp programları, rahatsızlıklardan dolayı bireylerin nasıl etkilendikleri ve ihtiyaçları üzerine odaklanmalıdır. Bu kapsamda, farklı araştırmacılar rekreasyon terapisi kampları ve etkilerine ilişkin farklı gruplar üzerinde çeşitli çalışmalar gerçekleştirmişlerdir. Genel olarak bir sınıflama yapılırsa, çalışmaların yaş gruplarına (Kiernan vd. 2004; Watson vd. 2010), hastalıklara (Török vd. 2006; Hill ve Jim Sibthorp 2006; Bekesi vd. 2011), engelli gruplarına (Bedini 2000; Blinde ve McClung 1997) ve bağımlı gruplarına (Bennett 1998) yönelik gerçekleştirildiği görülmektedir.

\section{Sosyal Özyeterlilik Kuramı}

Sosyal özyeterlilik, Bandura (1986) tarafından geliştirilen ve kişisel, çevresel ve davranışsal faktörler gibi değişik faktörlerin etkileşimi sonucu oluşan insan davranışlarının tanımlandı ̆̆ 1 "Sosyal Bilişsel Kuramın" bir bileşenidir. Kişisel faktörler, bireyde mevcut olan boy, kilo gibi biyolojik faktörlerin yanında özyeterlilikle ilişkili faktörleri de ifade etmektedir (Wise 2002). Çevresel faktörler, hava durumu ve fiziki ortamin etkileri de dahil olmak üzere bireyin dışında meydana gelen faktörleri ifade etmektedir. Davranışsal faktörler ise birey tarafından gerçekleştirilen davranışları ifade etmektedir. Davranışsal faktörler veya sosyal performans sosyal yeterliliğin göster- 
geleridir. Sosyal yeterliliğin artması durumunda, sosyal ortamlardaki bireysel sosyal performans da artmaktadır (Bandura 1997).

Özyeterlilik, olası durumları yönetmek için eylemleri organize etmek ve yürütmek için yeteneklere olan inanç olarak tanımlanmaktadır (Bandura 1997). Bireyin özyeterlilikle ilgili alg1$\mathrm{S1}$, hangi faaliyetleri gerçekleştirip gerçekleştiremeyeceğine, faaliyete ne kadar zaman, kaynak ve çaba harcayacağına, denemeler ve zorluklarla karşılaşıldığında o kişinin ne kadar süre bu faaliyeti yapmaya devam edeceğine etki etmektedir. Yüksek düzeyde özyeterliliği olan bireyler, yeni faaliyetlere katılmakta, yeni faaliyetlere daha fazla zaman, çaba ve kaynak ayırmakta ve bu faaliyetlere daha uzun süre katılmaktadır (Bandura 1997).

Sosyal özyeterlilik, özyeterliliğin değişik bir boyutudur. Bireyin sosyal özyeterliliği, bireyin sosyal hayatta nasıl hareket edeceği konusunda çok etkilidir. Yeni arkadaşlıklar edinmek, diyaloğa girmek, sosyal ilişkiler geliştirmek ve güçlendirmek sosyal özyeterliliğin değerlendirilebileceği göstergelerdendir. Sosyal özyeterlilik, bireylerin performanslarından dolayı elde ettiği başarılar, deneyimler, sözlü ikna ve fizyolojik göstergelerden etkilenmektedir. (Bandura 1997).

Bireyin sosyal özyeterliliği, bu kaynaklardan elde ettiği bilgiye göre güçlenmekte veya zayıflamaktadır. Performans başarıları, kişisel yeterliliği doğrudan etkilediği için sosyal özyeterliliğin güçlendirilmesi için en önemli bilgi kaynağıdır. Genellikle bir davranış başarı ile sonuçlanırsa özyeterliliğe etkisi güçlenmektedir ve tersine performans başarısız olursa etki zayıflamaktadır. Diğer bir bilgi kaynağı ise deneyimlerdir ve bireyin belirli bir davranışı sergilemesi sonucunda gözlemlediği ve elde ettiği birikimlerdir. Birey kendisiyle benzer bireysel özelliklere sahip olan kişilerin başarılarını gözlemeyerek kendisinin de bir davranışının başarı ile sonuçlanıp sonuçlanamayacağını düşünebilir. Başkalarının başarması kendisinin de başarabileceğini düşüncesini oluşturabilir. Bu durum başarısızlık için de geçerlidir. Benzer bireysel özelliklere sahip olan bireyin başarısızlığı bireyin kendisinin de başarısız olacağını düşünmesine neden olabilir. Başarılı ola- bileceği düşüncesi sosyal özyeterliliği arıtırken başarısızlık düşüncesi ise özyeterliliğini azaltabilir. Bunun yanında birey eğer, bir davranışı sergilerken zorluklarla karşılaşıp başarıya ulaşırsa, bir davranışı çok kolay bir şekilde sergileyip başarıya ulaşmasından daha fazla tatmin olmaktadır.

Bireyin sosyal özyeterliliğinin geliştirilmesinde diğer bir kaynak ise sözlü iknadır. Saygın, yetkin veya konusunda bilgili ve güvenilir bir kişiden gelen olumlu ifadeler bireyin özyeterliliğine olan inancını geliştirebilmekte ve özyeterliliğini artırmaktadır. Birey, sosyal performansı konusunda olumlu olduğu zaman özyeterliliği de güçlenmektedir (Bandura 1997). Bunun tam tersi olarak, güvendiği diğer kişilerin bireyin sosyal başarısı konusunda şüphe duyduğu ya da belirsizlik hissettiğini ifade etmesi, bireyin sosyal özyererliliğ̈ini zayıflatabilir. Sosyal özyeterliliğin geliştirilmesinde son kaynak fizyolojik göstergelerdir. Bireyin fiziksel olarak hissettiği bazı göstergeler onun sosyal özyeterliliği üzerinde etkilidir. Bu fiziksel göstergeler bireyin yetenek eksikliği veya başarısız olma durumu ile ilişkiliyse sosyal özyeterlilik zayıflamakta, bedenin başarı doğrultusunda heyecan yaşaması gibi olumlu göstergeler ise sosyal özyeterliliği güçlendirmektedir.

\section{YÖNTEM}

Çalışmanın amacı, bireylerin fiziksel, psikolojik ve sosyal yönden olumlu kazanımlar sağlaması$\mathrm{n} ı$ amaç edinen rekreasyon terapisi kamplarının sosyal etkilerinin değerlendirilmesine yönelik derleme bir çalışma gerçekleştirmektir. Bu kapsamda Google akademik üzerinden ulusal yazın "rekreasyon terapisi ve kamp" anahtar kelimesi kullanılarak taranmış ve bu alanda gerçekleştirilen ampirik bir çalışma bulunamamıştır. Rekreasyon terapisi kamplarının olumlu etkilerine dikkati çekmek ve bu alanda çalışma gerçekleştirmeye teşvik etmek amaciyla bu derleme makale hazırlanmıştır. Bu bağlamda rekreasyon terapisi ve sosyal etkilerine yönelik olarak gerçekleştirilen uluslararası araştırmalar incelenmiştir. İkincil veriler kapsamında yapılmış olan araştırmaların gözden geçirilmesi, değerlendirilmesi, yorumlanması ve senteze yönelik derlenmesi çalışmanın temel yöntemini oluşturmaktadır. 


\section{REKREASYON TERAPISININ SOSYAL ETKILERINE YÖNELIK YAZIN BULGULARI}

Rekreatif faaliyetlerin sosyal yönünün önemi dikkat çekicidir. Geçmişte yapılan çalışmalar, sosyal özyeterliliğin yaşam memnuniyeti üzerinde artış sağladığ1 (Hampton 2000) ve genel işlevsellikte iyileşme sağladığı gibi sağlıkla ilişkili olumlu çıktıları (Rejeski vd. 2001) ortaya konmuştur. Sosyal yeterlilik ve performansın rekreasyon terapisi uygulamalarıyla geliştirildiği yapılan çalışmalarla tespit edilmiştir (Tate ve Ellis 1997; Harrison ve McGuire 2008). Sosyal özyeterliliğin geliştirilmesi performans başarılarının artması, deneyim kazanılması, ikna edici mesajların verilebilmesi ve fizyolojik yönden olumlu sinyallerin alınması konularında bireyi güçlendirmektedir (Bandura 1997). Gerçekleştirilen araştırmalar rekreasyon terapisi ve bu kapsamda gerçekleştirilen kampların bireyin sosyal özyeterliliğinin artırılması konusunda olumlu etkileri olduğu tespit edilmiştir (Meltzer ve Rourke 2005; Harrison ve McGuire 2008). Örneğin rekreasyon terapisi kamplarının, çocuk ve gençlerin kendine verdikleri değer ve sosyal kabullenme düzeylerinde artış olduğuna yardımcı olduğu ve diğer bireylerle ilişki kurmada çok önemli bir deneyim kazandırdı ğ miştir (Meltzer ve Rourke 2005).

Rekreasyon terapisi gibi organizasyonlar, aynı yaş veya hastalık grubunda olan bireylerin aynı zamanda bir arada olduğu ve tıbbi durumları ile ilgili serbest bir ortamda etkileşime girdikleri bir ortam yaratmaktadır. Bunun yanında, sosyal bağımsızlığın güçlendirildiği, bireylerin liderlik deneyimi yaşama fırsatı yakalayabildiği, sosyal özyeterliliği ve performansı artıran eşsiz organizasyonlardir (Thurber vd. 2007). Rekreasyon terapisinin bireyi yalnızlaştıran psikolojik bir problem olan depresyonun azaltılmasina ve sosyal özyeterliliğin artırılmasına yardımcı olmak için kullanılan temel bir uygulama olduğu ileri sürülmüştür (Maughan ve Ellis 1991).

Török ve diğerleri tarafından (2006) gerçekleştirilen çalışmada rekreasyon terapisi kamp programlarının kanser ve diyabet hastası çocuklarda etkileri incelenmiştir. Çalışmada, 97 katılımcının (52 kanser, 45 şeker hastası) yer almıştır. Bu çalışma kapsamında ölçme aracı olarak, Rosen- berg Benlik Saygısı Ölçeği, Genel Algılanan ÖzYeterlilik Ölçeği ve Kaygı Envanteri kullanılmıştır. Katılımcilara kamp öncesinde, sonrasında ve kamptan iki ay sonra bu ölçekler uygulanmıştır. Sonuç olarak, benlik saygısı ve özyeterlilikte anlamlı ve pozitif yönde bir değişim olduğu belirlenmiştir.

15 Avrupa ülkesinde çocuklar için oluşturulan rekreasyon terapisi kamp programlarına katıl1mın çıktılarını belirlemek amacıyla bir çalışma tasarlanmıştır (Kiernan, 2004). Bu kampın amac1 fiziksel, sosyal ve psikolojik çıktılarının belirlenmesidir. Hedef kitle olarak kronik rahatsızlığa sahip çocuklar belirlenmiştir. Bu çocuklara kendilerinin belirttiği fiziksel rahatsızlıklar ve etkileri sorulmuştur. Bunun yanında Benlik Sayg1sı ve Yaşam Kalitesi ölçekleri (12 Avrupa dili) kullanılarak çocukların benlik saygısı ve yaşam kalitesi algılarına ilişkin değerlendirme yapmak planlanmıştır. Bu kapsamda üç farklı zaman diliminde veri toplama aşaması gerçekleştirilmiştir. Çocukların kendi belirttikleri fiziksel rahatsızlıklar, benlik saygısı ve yaşam kalitesine ilişkin anket formu kamp başlamadan önce, kamp bittikten sonra ve 6 ay sonra tekrar uygulanmıştır. Çalışma sonucunda elde edilen bulgulara göre, fiziksel özelliklerdeki iyileşmenin çocukların psikolojileri ve yaşam kalitelerinde de kısa ve uzun dönemde etkili olduğu tespit edilmiştir. Bunun yanında, benlik saygısı ve fiziksel çekicilik arasında ilişkide pozitif bir değişiklik olduğu belirlenmiştir. Çocukların yaşları ve hastalıklarına göre ayrım yapılarak gerçekleştirilen analizlerde kampın olumlu çıktıları olduğu ortaya konmuştur.

Rekreasyon terapisi kamp programına katılan kronik rahatsızlığı olan çocuklarda ve gençlerde kampın sağlığa dayalı yaşam kalitesindeki etkilerini belirlemek amacıyla başka bir çalışma gerçekleştirilmiştir (Bekesi vd. 2011). Bu çalışmanın amacı doğrultusunda veri toplamak amacıyla sağlığa dayalı yaşam kalitesi ölçeği (kidscreen-52) uygulanması planlanmıştır. Onkolojik, diyabetik, bağışıklık sistemi hastalıkları olan yaş aralığ1 10-18 olan 115 çocuk ve genç bu kampa dahil edilmiş ve araştırma kapsamına alınmıştır. Bu kapsamda, araştırma dahilinde kronik 
rahatsızlığı olan çocuk ve gençlere kampın başlangıcından iki ay önce ve kampın bitişinden iki ay sonra sağlığa dayalı yaşam kalitesi ölçeği uygulanmıştır. Veriler analiz edilip bulgular yorumlanmıştır ve sonucunda kamp programının sağlığa dayalı yaşam kalitesi üzerinde tüm hastalık grupları için olumlu etkisi tespit edilmiştir. Kamp deneyimi ile deneyim çocukların algıları artmış ve özellikle 14 yaş altında olanların bireysellikleri azalma olduğu tespit edilmiştir.

Lavigne ve Faider-Rouman (1992) tarafından gerçekleştirilen çalışmada kronik rahatsızlığı olan çocuklarda, duygulanım bozukluğu, özgüvensizlik, sosyal ve davranışsal zorlukları içeren genel uyum sorunlarının artan bir şekilde ortaya çıktığ 1 belirtilmektedir. Dişarda grupla gerçekleştirilen faaliyetler çocukların ve gençlerin özgüvenlerini geliştirmekte ve karşılıklı iletişimlerini güçlendirmektedir (Watson 1995). Kamp programlarıyla çocuklar eğlenirken de fiziksel, psikolojik ve sosyal yönden gelişim sağlayabilmekte ve olumlu deneyimler kazanabilmektedirler.

\section{TARTIŞMA VE SONUÇ}

Sonuç olarak, rekreasyon terapisini bireyin sosyal sağlığı üzerinde olumlu etkilerinin olduğunu destekleyen birçok çalışma gerçekleştirilmiştir. Bu kapsamda gerçekleştirilen kampların bugün ve gelecekte olumlu etkileri artarak devam edebilir. Bu kapsamda kamplarda bireylerin kendi rahatsızlıklarına ilişkin bilgi edilmeleri (Bluebond- Langner vd. 1990) dışında tıbbi gelişmeleri de takip edebilme fırsatı yakalamaktadırlar. Özellikle kronik bir rahatsızlı̆̆a sahip olan gençlerde rekreasyon terapisi kamplarının sosyal kabul düzeyinde, özdeğer algısında artış ve rahatsızlığı ile daha barışık bir şekilde yaşamalarında etkili olduğu belirlenmiştir (Meltzer ve Rourke 2005).

Bu kamplar aynı yaşta, aynı hastalıkta veya engel türünde bireylerin bir araya gelmesini sağladığ1 için aynı durumda olan kişilerle sosyal iletişim ve etkileşim kurmalarına olanak tanımaktadır. $\mathrm{Bu}$ iletişim süreci de onları rahatsızlıklarıyla başa çıkma konusunda mücadele etmelerini desteklemekte (Meltzer ve Rourke 2005) ve hayata karşı olumsuz düşüncelerinde uzaklaşmalarını sağlamaktadır. Bunun yanında kampa katılanların bireysel bağımsızlıklarını kazanmaya ve liderlik yeteneklerini geliştirmeye yardımcı olmaktadır. Açık havada sosyal ilişkileri geliştirerek bireyin kendisine olan sosyal özyeterlilikle ilgili kendine güvenlerini geliştirmektedir (Thurber vd. 2007).

Sonuç olarak rekreasyon terapisi kamplarının bireyin genel sağlığı üzerindeki etkileri yadsınamaz bir gerçektir. Bu kapsamda hem fiziksel hem sosyal hem de psikolojik yönden olumlu etkileri farklı yaş, hastalık, engel ve bağımlı gruplarda yapılan çalışmalarda belirlenmiştir. Bu makalede rekreasyon terapisi kamplarının yalnızca sosyal yönden olumlu etkileri üzerinde durulmaktadır. Gerçekleştirilen ulusal yazın taramasında ampirik çalışmaların genel olarak relreatif faaliyetlere katılma veya katılmama nedenleri, bunun yanında rekreatif faaliyetlere katılımın önündeki engeller çerçevesinde gerçekleştirildiği görülmektedir. Bunun yanında bu alanda gerçekleştirilen en temel çalışma, terapatik rekreasyon bir örnek uygulama olan "Otistik Bireyler Spor Eğitimi Projesi"dir. Rekreatif etkinliklerin antrometrik ve fizyolojik özelliklere etkisi (Taşkıran ve Kaya 2015), kadınlarda spor etkinliklerine katılımlarının boş zaman tatmini ve yaşam kalitesine etkileri (Eruzun 2017), terapatik rekreasyonel aktivitelere katılımın yaşlıların boş zaman, yaşam tatmini ve yaşam kalitesine etkilerine (Sevil 2015) yönelik çalışmalar da rekreatif etkinliklere katılımın etkisi incelenmektedir. Bu çalışmalar rekreatif faaliyetlere katılımın sosyal etkileri ile ilişkilidir; ancak belirli bir hedef grubuna yönelik olarak planlanan rekreasyon terapisi kampları ile ilgili gerçekleştirilen ampirik bir çalışma bulunamamıştır. Hem bu kampların organize edilip hedef gruba yönelik uygulanması ve aynı zamanda kampların etkililiğinin değerlendirildiği çalışmaların gerçekleştirilmesi konusunda alan yazında eksikliğin olduğu belirlenmiştir.

Rekreasyon terapisi kapsamında bir kamp programı hazırlamak multidisipliner bir yaklaşım gerektirmektedir. Bu kapsamda, farklı alanlarda uzman birçok uzmanın katılımı ile hedef kitleye yönelik kamp programının oluşturulması ve etkililiğinin değerlendirilmesi gerekmektedir. Bu 
konunun sadece kampa katılan bireyler kapsamında değil onların ailelerinin de ele alınarak değerlendirilmesi önemlidir. Bu nedenle, kampa katılan bireyin elde ettiği kazanım pozitif dışsallık yaratarak onların ailelerine, okul ortamina ve içinde bulunduğu sosyal topluluğa da olumlu katkı sağlayabilir. Tüm bu çerçevede, kampa katılanların ve ilişkide bulunduğu kişi veya grupları temel alan rekreasyon terapisi kamplarının sosyal etkilerine yönelik çalışmalar gerçekleştirilebilir.

\section{KAYNAKÇA}

Bandura A. (1997). Self-Efficacy: The Exercise of Control. New York: Freeman.

Bandura A. (1986). Social Foundations of Thought and Action: A Social Cognitive Theory. Englewood Cliffs New Jersey: Prentice Hall.

Bedini L. A. (2000). Just Sit Down So We Can Talk: Perceived Stigma and Community Recreation Pursuits of People with Disabilities, Therapeutic Recreation Journal, 34(1): 55-68.

Békési A., Török S., Kökönyei G., Bokrétás I., Szentes A. ve Telepóczki G. (2011). Health-Related Quality of Life Changes of Children and Adolescents with Chronic Disease After Participation in Therapeutic Recreation Camping Program, Health and Quality of Life Outcomes, 9 (1): 43-52

Bennett L.W., Cardone S. ve Jarczyk J. (1998). Effects of a Therapeutic Camping Program on Addiction Recovery: The Algonquin Haymarket Relapse Prevention Program, Journal of Substance Abuse Treatment, 15 (5): 469474.

Blinde E. M. ve McClung L. (1997). Enhancing the Physical and Social Self Through Recreational Activity: Accounts of Individuals with Physical Disabilities, Adapted Physical Activity Quarterly, 14 (4): 327-344.

Bluebond-Langner M., Perkel D., Gorertzel T., Nelson K. ve McGeary J. (1990). Children's Knowledge of Cancer and Its Treatment: Impact of an Oncology Camp Experience, The Journal of Pediatrics, 116 (2): 207-213.

Briery B. G. ve Rabian B. (1999). Psychosocial Changes Associated with Participation in a Pediatric Summer Camp, Journal of Pediatric Psychology, 24 (2): 183-190.

Caprara G. V., Steca P., Gerbino M., Paciello M. ve Vecchio G. M. (2006). Looking for Adolescents' Well-Being: SelfEfficacy Beliefs As Determinants of Positive Thinking and Happiness, Epidemiologia and Psichiatria Science, 15 (1): 30-43.

Eruzun C. (2017). Kadınların Spor Etkinliklerine Katılımlarının Boş Zaman Tatmini ve Yaşam Kalitesine Etkilerinin Araştırılması: B-Fit Spor Merkezleri Üyeleri Örneği. (Basılmamıs Yükseklisans Tezi). Bartın: Bartın Üniversitesi Eğitim Bilimleri Enstitüsü.
Hampton N. Z. (2000). Self-Efficacy and Quality of Life in People with Spinal Cord Injuries in China, Rehabilitation Counseling Bulletin, 43(2): 66-74.

Harrison M. M. ve McGuire, F. (2008). An Investigation of the Influence of Vicarious Experience on Perceived SelfEfficacy, American Journal of Recreation Therapy, 7(1): 10-16.

Hill E. ve Sibthorp J. (2006). Autonomy Support at Diabetes Camp: A Self-Determination Theory Approach to Therapeutic Recreation, Therapeutic Recreation Journal, 40 (2): 107-125.

Horn W., Yoels W., Wallace D., Macrina D. ve Wrigley M. (1998). Determinants of Self-Efficacy among Persons with Spinal Cord Injuries, Disability and Rehabilitation, 20 (4): 138-141.

Karaküçük, S. (1997). Rekreasyon (Boş Zamanları Değerlendirme) Kavram, Kapsam ve Bir Araștırma. İkinci Baskı. Ankara: Seren Ofset.

Karaküçük, S. (2012). Terapatik Rekreasyon Bir Örnek Uygulama OSEP (Otistik Bireyler Spor Eğitimi Projesi). Ankara: Gazi Kitabevi.

Kiernan G., Gormley M. ve MacLachlan M. (2004). Outcomes Associated with Participation in a Therapeutic Recreation Program for Children from 15 European Countries: Data from the 'Barrretstown Studies', Social Science \& Medicine, 59 (5): 903-913.

Kumar R. ve Lal R. (2006). The Role of Self-Efficacy and Gender Difference among Adolescents, Journal of the Indian Academy of Applied Psychology, 32 (3): 345-350.

Lavigne J.V. ve Faier-Rouman J. (1992). Psychological Adjustment to Pediatric Physical Disorders: A MetaAnalytic Review, Journal of Pediatric Psychology, 17 (2): 133-157.

Maughan M. ve Ellis G. G. (1991). Effect of Efficacy Information during Recreation Participation on Efficacy Judgments of Depressed Adolescents, Therapeutic Recreation Journal, 25(1): 50-59.

Meltzer L. J. ve Rourke M. T. (2005). Benefits of Social Comparison, Children's Health Care, 34(4): 305-314

Orbell, S., Johnston M., Rowley D., Davey P. ve Espley A. (2001). Self-Efficacy and Goal Importance in the Prediction of Physical Disability in People Following Hospitalization: a Prospective Study, British Journal of Health Psychology, 6 (1): 25- 40.

Passmore A. (2004). A Measure of Perceptions of Generalized Self-Efficacy Adapted for Adolescents, Occupational Therapy Journal of Research, 24 (2): 64-71.

Punnett A.F. ve Thurber S. (1993). Evaluation of The Asthma Camp Experience for Children, Journal of Asthma, 30 (3): 195-198.

Rejeski W. J., Miller M. E., Foy C., Messier S. ve Rapp S. (2001). Self-Efficacy and the Progression of Functional Limitations and Self-Reported Disability in Older Adults with Knee Pain, The Journals of Gerontology Series B: Psychological Sciences and Social Sciences, 56 (5): 261-265.

Shank J. ve Coyle C. (2002). Therapeutic Recreation in Health Promotion and Rehabilitation. State College PA: Venture. 
Sevil T. (2015). Terapatik Rekreasyonel Aktivitelere Katılımın Yaşlıların Algıladıkları Boş Zaman Tatmini, Yaşam Tatmini ve Yaşam Kalitesine Etkisi. (Basılmamıs Doktora Tezi). Eskişehir: Anadolu Üniversitesi Sağlık Bilimleri Enstitüsü Beden Eğitimi ve Spor Anabilim Dalı.

Taşkıran A. ve Kaya İ. (2015). Huzurevinde Kalan Yaşlılara Uygulanan 12 Haftalık Sportif Rekreasyon Program1nın Bazı Antropometrik ve Fizyolojik Parametrelere Etkisinin İncelenmesi, Sportif Bakış: Spor ve Ĕ̆gitim Bilimleri Dergisi, 2 (1): 23-30.

Tate D. ve Ellis G. (1997). Effects of Facilitation Techniques on Challenge Initiative Related Outcomes among Adolescents Receiving Mental Health Services, Therapeutic Recreation Journal, 31(2): 92-107.

Thurber C.A., Scanlin M.M., Scheuler L. ve Henderson K.A. (2007). Youth Development Outcomes of the Camp Experience: Evidence for Multidimensional Growth, Journal of Youth Adolescence, 36 (3): 241-254.

Török S., Kökönyei G., Károlyi M.A., Ittzés A. ve Tomcsányi T. (2006). Outcome Effectiveness of Therapeutic Recreation Camping Program for Adolescents Living with Cancer and Diabetes, Journal of Adolescent Health, 39 (3): 445-447.

Tütüncü Ö. (2012). Rekreasyon ve Rekreasyon Terapisinin Yaşam Kalitesindeki Rolü, Anatolia: Turizm Araştırmalar Dergisi, 23 (2): 248 - 252.

Tütüncü Ö. ve Aydın İ. (2016). Engelsiz Turizm Kapsamında Rekreasyon Terapi Kamplarının Değerlendirilmesi, Anatolia: Turizm Araștırmaları Dergisi, 27 (2): 290-297.
Walker D. A. ve Pearman D. (2009). Therapeutic Recreation Camps: An Effective Intervention for Children and Young People with Chronic Illness?, Archives of Disease in Childhood, 94 (5): 401-406.

Watson A., Hilton D. ve Hackett D. (2010). Therapeutic Recreation Camps to Provide a Residential Experience for Young People in Transition to Adult Renal Units, Pediatric Nephrology, 25 (4): 787-788.

Watson A. R. (1995). Strategies to Support Families of Children with End-Stage Renal Failure, Pediatric Nephrology, 9 (5): 628-631.

Williams K. E. ve Bond, M. J. (2002). The Roles of SelfEfficacy, Outcome Expectancies and Social Support in the Self-Care Behaviors of Diabetes, Psychology, Health \& Medicine, 7 (2): 127-141.

Winfree C., Williams R. ve Powell G. (2002,). Children with Cancer: Positive Benefits of Camp, Camping Magazine, 75(6): 26-33.

Wise J. B. (2002). Social cognitive theory: A framework for therapeutic recreation practice, Therapeutic Recreation Journal, 34(4): 335-351.

İpek AYDIN, Uzman, Dokuz Eylül Üniversitesi, Spor Bilimleri ve Teknolojisi Yüksekokulu, Rekreasyon Bölümü.

E-posta:ipek.aydin@deu.edu.tr

ORCID: 0000-0002-9355-5712

Özkan TüTÜNCÜ, Prof. Dr., Dokuz Eylül Üniversitesi, Spor Bilimleri ve Teknolojisi Yüksekokulu, Rekreasyon Bölümü.

E-posta: ozkan.tutuncu@deu.edu.tr

ORCID: 0000-0002-2482-0893 